\title{
DESAFIOS DA CPA APÓS 11 DE JUNHO DE 2017
}

\author{
INDAIAL/SC JULHO/2018
}

\begin{abstract}
Elisabeth Penzlien Tafner - UNIASSELVI - eptafner@gmail.com
\end{abstract}
Tipo: Relato de Experiência Inovadora (EI)

Categoria: Pesquisa e Avaliação

Setor Educacional: EDUCAÇÃO SUPERIOR

\begin{abstract}
RESUMO
Segundo dados do Censo (2016), os cursos de graduação a distância ainda têm se mostrado como uma opção significativa. Neste relato de experiência inovadora, será apresentado como a qualidade desses cursos tem sido acompanhada pela Comissão Própria de Avaliação - CPA, de uma IES do Vale do Itajaí, após a divulgação da portaria 11 de junho e do novo Instrumento de Avaliação Institucional Externa - Presencial e a Distância. Realizado a partir da análise das considerações de comissões externas em processos de recredenciamento de polos, o texto evidencia que a IES tem pautado seu processo de expansão de polos com a manutenção da qualidade e que o novo Instrumento deve colaborar para que, independentemente do número de polos, a oferta dos cursos e serviços seja realizada em coerência com o previsto na meta 13 do PNE.
\end{abstract}

Palavras-chave: Comissão Própria de Avaliação - Polos de Apoio Presencial - Comissões Externas. 


\section{INTRODUÇÃo}

Realizar um curso de graduação a distância deixou de ser uma possibilidade para tornarse uma realidade. A organização dos modelos de oferta em EAD tem conquistado uma parcela significativa de alunos, segundo o Censo EAD (2016).

A manutenção dos números de matrícula, em grande parte das IES que participaram do Censo, sugere que os Referenciais de Qualidade para a Educação Superior a Distância (2007) têm norteado a atuação das IES, já que o documento subsidia os instrumentos regulatórios.

Neste sentido, destacamos a meta 13 do Plano Nacional de Educação (BRASIL, 2014, p.44) relativa à elevação da qualidade da educação superior, especialmente através da estratégia de fortalecimento das comissões próprias de avaliação, "[...] induzindo processo contínuo de autoavaliação das instituições [...] bem como a aplicação de instrumentos de avaliação que orientem as dimensões a serem fortalecidas". Além disso, tendo em vista a possibilidade concedida às IES, já credenciadas para a modalidade EAD, conforme o conceito institucional, de abrirem até 250 polos por ano, através da portaria 11 de junho de 2017 (BRASIL, 2017a), o papel das comissões pode ser considerado decisivo para a manutenção da qualidade dos cursos ofertados nos polos de apoio presencial.

Desta forma, este relato pretende fazer um retrospecto do trabalho realizado pela Comissão Própria de Avaliação - CPA de uma Instituição do Vale do Itajaí - SC, antes da divulgação da portaria de 11 de junho de 2017, bem como apresentar os desafios desta comissão face à expansão de polos da IES e ao novo Instrumento de Avaliação Institucional Externa - Presencial e a Distância (2017b).

\section{HISTÓRICO DA COMISSÃO PRÓPRIA DE AVALIAÇÃO - CPA}

O processo de Autovaliação Institucional (Al) da Instituição - procura implementar uma prática de permanente reflexão autocrítica, estimulando o debate interno e externo entre todos os agentes envolvidos (acadêmicos, docentes, gestores, técnicos-administrativos, mantenedores e comunidade).

A Al, baseada no processo constante de busca da qualidade da IES, dos cursos, e do desempenho de cada sujeito interveniente, pressupõe uma não acomodação, exigindo uma predisposição à mudança que acompanhe a dinâmica científica, cultural, organizacional e tecnológica. 
Os resultados da AI norteiam os rumos da IES, bem como o estabelecimento dos pontos fortes da IES, sendo, portanto, um instrumento valioso para a consolidação dos desejos, sonhos e aspirações da comunidade acadêmica.

Disseminada como uma excelente ferramenta de diagnóstico, correção de rumos, acompanhamento e controle dentro de uma abordagem construtiva e dialógica, considera também de forma especial as contribuições do trabalho realizado pelas avaliações externas, cuja visão, apesar de distanciada, é fundamental para o contínuo repensar das ações da CPA da IES.

\section{CONTRIBUIÇÕES DAS AVALIAÇÕES EXTERNAS ATÉ 11 DE JUNHO DE 2017}

Anteriormente à publicação da portaria de 11 de junho, a IES recredenciou 20 polos de apoio presencial, entre junho de 2016 e abril de 2017. Neste processo, o diálogo entre a CPA da IES e as comissões externas oportunizou não apenas a verificação das condições de tais polos para oferta dos cursos, mas também a avaliação do trabalho da CPA da IES, proporcionando assim uma constante revisão de suas ações, para além daquelas já realizadas inerentemente, tendo em vista o volume de acadêmicos atendidos à época, aproximadamente 100.000, distribuídos em 48 polos de apoio presencial. Esses recredenciamentos foram pautados pelo Instrumento de Avaliação Institucional - Externa (BRASIL, 2010).

No quadro a seguir estão transcritos os fragmentos dos relatos das 20 comissões externas, que avaliaram o trabalho realizado pela CPA da IES, nos processos de recredenciamento dos polos. Por motivos institucionais, o nome dos polos foi substituído pelas letras do alfabeto. Os grifos são da autora e norteiam as considerações que serão feitas após o quadro.

Quadro 1 - Considerações sobre a dimensão 8 


\begin{tabular}{|c|c|c|}
\hline $\begin{array}{l}\text { Polo e } \\
\text { periodo da } \\
\text { visita }\end{array}$ & Avaliadores "adhoc" & CPA \\
\hline $\begin{array}{l}\text { A-BA: } \\
09 / 08 / 2016 \text { a } \\
13 / 08 / 2016\end{array}$ & $\begin{array}{l}\text { 8.1Verificou-se que há coerência entre o planejamento e avaliação com o que está } \\
\text { explicitado no PDI [...] sobretudo a partir da nova gestão instalada após a mudança de } \\
\text { mantença.[...]. Há também um evento anual destinado à socialização dos resultados, } \\
\text { que ficam acessiveis a toda a comunidade acadêmica. Na reunião com os discentes do } \\
\text { Polo foi relatado que todos conhecem o trabalho realizado pela CPA e que, ao longo } \\
\text { dos anos, foram implementadas diversas melhorias no Polo, consequentes ao } \\
\text { processo autoavaliativo. [...] Nos Polos, de acordo com as reivindicaçôes da comunidade } \\
\text { acadêmica, são realizadas as açôes e divulgadas por meio de decalques de parede } \\
\text { (adesivos), por dimensão do SINAES, postados nos distintos ambientes (recepção, } \\
\text { biblioteca, salas de aula, murais, etc.). [...]. }\end{array}$ & 4 \\
\hline $\begin{array}{l}\text { B-RS: } \\
31 / 07 / 2016 \text { a } \\
04 / 08 / 2016\end{array}$ & $\begin{array}{l}\text { [...]. Na modalidade a distância, os resultados são apresentados e discutidos diretamente nos } \\
\text { Polos de Apoio Presencial, conforme atas disponibilizadas. [...] Pode-se verificar em todas } \\
\text { as entrevistas com os seguimentos do polo que a IES tem, a partir dos resultados das } \\
\text { avaliaçōes, das fragilidades e potencialidades percebidas, procurado implementar } \\
\text { adequadamente açőes acadêmico-administrativas, com o intuito de melhorar e } \\
\text { aperfeiçoar o Projeto Politico Pedagógico da Instituiçäo. [...]. }\end{array}$ & 4 \\
\hline $\begin{array}{l}\text { C-MS: } \\
31 / 07 / 2016 \text { a } \\
04 / 08 / 2016\end{array}$ & $\begin{array}{l}\text { [...]. No polo de } \mathrm{C} \text { os discentes colocaram que participaram do processo e receberam } \\
\text { retorno [...]. No polo de } \mathrm{C} \text { foi citada uma fragilidade com alguns tutores o que } \\
\text { posteriormente foi sanada devido aos relatórios produzidos pela CPA. Na reunião com } \\
\text { os discentes do polo os mesmos disseram conhecer o trabalho realizado pela CPA e que ao } \\
\text { longo dos anos foram implementadas melhorias no polo. [...] }\end{array}$ & 4 \\
\hline $\begin{array}{l}\text { D-SC: } \\
25 / 09 / 2016 \text { a } \\
29 / 09 / 2016\end{array}$ & $\begin{array}{l}\text { [...] As açōes da CPA são divulgadas por meio do portal da IES, cartazes e adesivos } \\
\text { colados na parede e nas lousas. Nas reuniőes com todos os segmentos da IES, } \\
\text { constatou-se que há um geral conhecimento da CPA, de sua atuação e dos resultados } \\
\text { avaliativos que aparecem em seus relatórios periódicos. [...] }\end{array}$ & 4 \\
\hline $\begin{array}{l}\text { E-SC: } \\
31 / 07 / 2016 \text { a } \\
04 / 08 / 2016\end{array}$ & $\begin{array}{l}\text { 8.1 a } 8.3 \text { [...] Os relatórios gerados pela CPA e os relatos dos discentes e docentes } \\
\text { revelam que o instrumento é feito de forma participativa e o envolvimento da } \\
\text { comunidade acadêmica é significativo, com participação de aproximadamente } 60 \% \text { dos } \\
\text { alunos dos cursos EaD, oferecendo um panorama confiável da realidade da IES. [...]. } \\
\text { Segundo depoimento dos discentes há solução de alguns problemas apontados na } \\
\text { consulta. [...] Os membros da CPA são qualificados, estão comprometidos com o processo } \\
\text { avaliativo e encontram respaldo na Direção. }\end{array}$ & 3 \\
\hline $\begin{array}{l}\text { F-PR: } \\
\text { 26/06/2016 a } \\
30 / 06 / 2016\end{array}$ & $\begin{array}{l}\text { 8.1 a } 8.3 \text { [...] A Comissão Externa de Avaliação constatou na entrevista com os } \\
\text { membros da CPA que a mesma necessita ter critérios de composição mais } \\
\text { adequados, permitindo a escolha de seus membros através de seus pares o que } \\
\text { seguramente permitirá uma maior independência a mesma. [...]. Verificou-se que } \\
\text { ocorre evolução institucional com a aplicação dos resultados encontrados nas } \\
\text { pesquisas realizadas pela CPA. As pesquisas são feitas com periodicidade anual, sendo } \\
\text { que até o ano de } 2014 \text {, a CPA aplicou questionários para todos os membros da comunidade } \\
\text { acadêmica e em } 2015 \text { esta aplicação se deu somente aos discentes [...] }\end{array}$ & 3 \\
\hline $\begin{array}{l}\text { G-SC: } \\
09 / 08 / 2016 \text { a } \\
13 / 08 / 2016\end{array}$ & $\begin{array}{l}\text { [...] A IES tem se preocupado em avaliar suas atividades acadêmicas, administrativas e de } \\
\text { infraestrutura, tanto que iniciou seu sistema de autoavaliação no ano de 2000. Na época, } \\
\text { teve como início a aplicação de questionário especifico, buscando informaçães sobre } \\
\text { questôes acadêmicas e administrativas, a fim de começar seu processo de melhorias que } \\
\text { vem se repetindo e aprimorando ano após ano.[...]. }\end{array}$ & 4 \\
\hline $\begin{array}{l}\text { H-BA: } \\
25 / 10 / 2016 \text { a } \\
29 / 10 / 2016\end{array}$ & $\begin{array}{l}\text { [...] Os estudantes do Polo de H/ BA entrevistados afirmaram que participam do processo de } \\
\text { autoavaliação institucional e demonstraram conhecimento dos resultados das avaliaçōes, } \\
\text { apesar de não lembrarem das informaçâes pontuais contidas nos cartazes fixados nas } \\
\text { paredes e murais do polo. Esses pequenos cartazes informam precisamente os problemas } \\
\text { apontados pela autoavaliação e as soluçôes adotadas pela IES. A comissão constatou pelas } \\
\text { entrevistas que a CPA vem contribuindo muito bem para a gestão, o melhoramento e o } \\
\text { crescimento da IES. [...] }\end{array}$ & 4 \\
\hline $\begin{array}{c}\mathrm{I}-\mathrm{GO} \\
05 / 03 / 2017 \text { a } \\
09 / 03 / 2017\end{array}$ & $\begin{array}{l}\text { [...] No polo de I, os resultados são apresentados e discutidos diretamente com os alunos, } \\
\text { tutores externos e servidores técnico-administrativos. Na visita "in loco" foi possivel observar } \\
\text { nos murais ações decorrentes dos resultados obtidos a partir dos relatórios da CPA.[...]. }\end{array}$ & 4 \\
\hline $\begin{array}{l}\mathrm{J}-\mathrm{RO} \\
28 / 03 / 2017 \text { a } \\
01 / 04 / 2017\end{array}$ & $\begin{array}{l}\text { [...] Cabe ressaltar que um dos representantes docentes possui grand } \\
\text { EAD.[...] Constatou-se que os resultados são adequadamente integra } \\
\text { decisórios nos diversos âmbitos de gestäo da IES, contribuindo para } \\
\text { da qualidade no desempenho acadêmico [...] }\end{array}$ & 4 \\
\hline $\begin{array}{c}\text { K-BA: } \\
04 / 10 / 2016 \text { a } \\
08 / 10 / 2016\end{array}$ & $\begin{array}{l}\text { [...] Verificou-se uma boa atuação da Comissão Própria de Avaliaçăo que tem buscado } \\
\text { aperfeiçoar seus instrumentos, a divulgaçăo e a participaçăo da comunidade acadêmica. [...] } \\
\text { A UNIASSELVI implanta adequadamente açōes acadêmico-administrativas baseadas nos } \\
\text { resultados das avaliaçő́es internas e externas. [...] }\end{array}$ & 4 \\
\hline $\begin{array}{l}\mathrm{L}-\mathrm{PR} \\
19 / 02 / 2017 \text { a } \\
23 / 02 / 2017\end{array}$ & $\begin{array}{l}\text { [...] Foi relatado que, permanentemente, a IES disponibiliza um sistema de avaliação } \\
\text { "Protocolo" onde as solicitaçőes săo preenchidas todo o ano, o que demonstra sua } \\
\text { responsabilidade em desenvolver aç̋eses acadêmicas e administrativas com vistas à melhoria } \\
\text { da qualidade da instituiçăo. [...] Na reuniăo com os alunos foi possivel perceber a } \\
\text { preocupaçăo da IES na participaçăo dos alunos da EAD nos processos avaliativos, e que } \\
\text { várias mensagens são disparadas ao longo do ano lembrando os alunos de participarem no } \\
\text { envio dos questionários respondidos. [...] }\end{array}$ & 4 \\
\hline $\begin{array}{l}\text { M-SP: } \\
09 / 08 / 2016 \text { a } \\
13 / 08 / 2016\end{array}$ & $\begin{array}{l}8.1 \text { a } 8.3 \text { [...] há divulgaçăo das análises e dos resultados das avaliaçōes, estando as } \\
\text { informaçoes correspondentes acessiveis à comunidade acadêmica através de adesivos nas } \\
\text { paredes, indicando o atendimento às solicitaçōes registradas pela CPA. [...]. A comissão } \\
\text { destaca, ainda, a possibilidade de desmembramento dos relatórios permitindo análise } \\
\text { especifica dos resultados obtidos na avaliaçăo do PAP de M. [...]. }\end{array}$ & 4 \\
\hline $\begin{array}{l}\text { N-RS: } \\
02 / 08 / 2016 \text { a } \\
06 / 08 / 2016\end{array}$ & $\begin{array}{l}\text { [...]A comissão constatou pelas entrevistas que a CPA vem contribuindo muito bem para a } \\
\text { gestăo, o melhoramento e o crescimento da IES. [...]. Os docentes entrevistados } \\
\text { manifestaram satisfação em pertencerem à Instituiçăo e os tutores presenciais igualmente } \\
\text { manifestaram-se satisfeitos em atuar no polo de } \mathrm{Ne} \text { em pertencer ao quadro funcional da } \\
\text { UNIASSELVI. [...]. }\end{array}$ & 4 \\
\hline $\begin{array}{c}\text { O-BA: } \\
15 / 11 / 2016 \text { a } \\
19 / 11 / 2016\end{array}$ & $\begin{array}{l}\text { [...]Dentre as açōes consequentes à autoavaliação institucional, ressaltam-se: ampliaçăo do } \\
\text { das instalaçōes fisicas, melhoria da infraestrutura da área de convivência e da } \\
\text { brinquedoteca. [...] }\end{array}$ & 3 \\
\hline $\begin{array}{c}\text { P-GO: } \\
02 / 04 / 2017 \text { a } \\
06 / 04 / 2017 \\
\end{array}$ & atende o alsposto no art. & 4 \\
\hline $\begin{array}{c}\text { Q-SC: } \\
25 / 09 / 2016 \text { a } \\
29 / 09 / 2016 \\
\end{array}$ & $\begin{array}{l}\text { ] esta Comissão de Avaliação entende que a IES apresenta de } \\
\text { erencial minimo de qualidade para a dimensão avaliada. }\end{array}$ & 4 \\
\hline $\begin{array}{l}\text { R-RS: } \\
\text { 22/05/2016 a } \\
\text { 26/05/2016 }\end{array}$ & $\begin{array}{l}\text { [...]No polo visitado, os discentes afirmaram que participaram do processo, mas năo tinham } \\
\text { recebido um retorno. No entanto, cartazes afixados nos distintos ambientes do polo expöem } \\
\text { as açōes institucionais que resultaram da avaliaçăo institucional.[...] No caso de } Q \text { as } \\
\text { melhorias mais percebidas foram na infraestrutura, conforme relatado na reuniăo com o } \\
\text { corpo discente.[...]. }\end{array}$ & 4 \\
\hline $\begin{array}{l}\text { S-ES } \\
07 / 02 / 2017 \text { a } \\
11 / 02 / 2017\end{array}$ & $\begin{array}{l}\text { Esta comissão entrevistou colaboradores de diferentes segmentos do polo [...] e todos } \\
\text { informaram que têm conhecimento da CPA e que são incentivados a participar da coleta de } \\
\text { dados (questionário), que é feita no sistema eletrônico. A amostragem de entrevistados ficou } \\
\text { reduzida em funçăo da crise de segurança que se encontrava o estado do Espirito Santo no } \\
\text { periodo da avaliação. [...]. }\end{array}$ & 4 \\
\hline $\begin{array}{l}\text { T-BA: } \\
04 / 10 / 2016 \text { a } \\
08 / 10 / 2016\end{array}$ & $\begin{array}{l}\text { [...] Com os dados em măo e também com os dados da Ouvidoria são elaborados os } \\
\text { resultados que são enviados a todos os setores e a partir dai são tomadas as medidas } \\
\text { cabiveis para sanar os problemas.[...] A IES implementa adequadamente suas ações, pois } \\
\text { foi confirmado em reunióes que os resultados da CPA já provocaram muitas mudanças } \\
\text { práticas no polo visitado. [...] }\end{array}$ & 5 \\
\hline
\end{tabular}


Fonte: Dados Institucionais

Os relatos feitos pelas comissões externas evidenciam que a atuação da CPA da IES vem realizando um trabalho importante junto aos polos de apoio presencial, destacandose com frequência o processo de divulgação dos resultados junto a todos os segmentos, especialmente pelo uso dos adesivos onde houve melhorias. Esta ação inclusive foi percebida como positiva pelos avaliadores, mesmo no momento em que os acadêmicos não se lembravam das melhorias. No momento da socialização, cada polo já recebeu seu resultado por categoria avaliada. Outra ação muito evidenciada foram os momentos de socialização nos diversos grupos, como estratégia para também manter a lembrança dos respondentes, contribuindo para que estes participem a cada edição da Al.

A comunicação da CPA também recebe reforço das coordenações de curso, através do envio de mensagens para acadêmicos e tutores participarem da $\mathrm{Al}$, o que contribui de maneira significativa nos $60 \%$ de participação dos acadêmicos nas Al. A parceria realizada com o setor de Ouvidoria da IES, bem como o canal de protocolo, destinado exclusivamente à CPA, também foram percebidos pelas comissões externas como estratégias constantes de comunicação dos polos com a IES, a fim de sanar fragilidades. Em relação ao relato do membro da equipe com expertise em EAD faz-se um contraponto com o relato acerca revisão de critérios de composição, ou seja, o que foi visto como fragilidade por uma comissão externa foi percebido pela outra como potencialidade. Em resumo, os relatos evidenciam que o planejamento e avaliação institucional na IES são realizados num quadro geralmente além do que expressa o referencial mínimo de qualidade, o que confirma a importância do trabalho de autoavaliação institucional realizado na IES desde 2000, quando ainda não havia a orientação legal do SINAES, mas sim uma meta institucional de busca pela qualidade nos cursos ofertados pela IES.

\section{O PAPEL DA CPA APÓS 11 DE JUNHO DE 2017}

A divulgação da portaria de 11 de junho, que estabelece normas para o credenciamento de instituições e a oferta de cursos superiores a distância, em conformidade com o Decreto n. 9.057, de 25 de maio de 2017 (2017c), permitiu maior celeridade às IES no seu processo de expansão, contudo trouxe algumas preocupações, quando considerada a meta 13 prevista no PNE.

$\mathrm{O}$ art. 12 da portaria de 11 de junho autoriza "as IES credenciadas para a oferta de cursos superiores a distância" (BRASIL, 2017a) a criar por ato próprio polos EAD, numa quantidade relativa ao conceito institucional. Este ato beneficia as comunidades até 
então não atendidas pelo ensino superior, mas amplia exponencialmente responsabilidade das comissões próprias de avaliação, pois os intervalos concedidos na portaria são bastante expressivos sob o ponto de vista da gestão.

Realizar o ciclo da $\mathrm{Al}$ em tantos polos novos é um desafio tanto para os profissionais dos polos que recebem tais orientações, quanto para os acadêmicos, cujo conhecimento da CPA também é mínimo ao adentrarem no ensino superior.

Desta forma, considerando-se a expansão proporcionada pela portaria e o novo Instrumento de Avaliação Institucional Externa - Presencial e a Distância, divulgado em outubro de 2017, no que tange ao Eixo 1 - Planejamento e avaliação institucional, o papel da CPA no acompanhamento da oferta dos cursos nos polos precisa ocorrer com um rigor ainda maior, em comparação àquele que já vinha sendo realizado, para que assegure a gestão e o crescimento da IES, conforme previsto no PDI da IES, independentemente da quantidade de polos que a IES detenha.

Neste sentido, o novo Instrumento de Avaliação Institucional Externa - Presencial e a Distância (2017b), destaca a importância do Relato Institucional no indicador 1.1, o qual não era explicitado no instrumento anterior. Contudo, o "RI foi concebido como uma inovação do Instrumento para Avaliação Institucional Externa (modalidade presencial) - 2014, publicado na Portaria no 92 de 31 de janeiro de 2014, que subsidia o ato de credenciamento e recredenciamento institucional e a transformação de organização acadêmica". Desta forma, os dados da EAD não são o foco do RI que será subsídio para o indicador 1.1, fonte de informações para o novo instrumento que atenderá instituições diversas, que ofertam a modalidade presencial ou a distância. Independentemente dessa lacuna, acredita-se que a avaliação deste documento com maior atenção, seja positivo para IES, a fim de promover melhorias no processo de registro e de acompanhamento das ações projetadas/concluídas, a fim de contemplar fluxos de análise, determinação e acompanhamento de providências pelas instâncias superiores.

Quanto ao indicador 1.2, a CPA da Instituição tem realizado a gravação de vídeos para ampliar a sensibilização de acadêmicos, da mesma forma que tem estudado estratégias como a criação de uma ferramenta para que os acadêmicos possam deixar seu relato acerca do conhecimento advindo da socialização dos resultados no polo de apoio presencial. No que diz respeito ao atendimento das necessidades institucionais como instrumento de gestão e ação da melhoria institucional, a autoavaliação institucional, tendo em vista o volume atual de polos da Instituição, motivou o desenvolvimento de um sistema para acompanhamento dos resultados pelos gestores no polo e na sede, o qual 
ainda tem sido objeto de aperfeiçoamento, com a contribuição de vários atores pedagógicos, que se utilizam dos resultados para gerir ações de natureza acadêmicoadministrativa.

O indicador 1.3, novidade tendo em vista a indicação "com abrangência de instrumentos de coleta", requer da CPA da IES a elaboração de um questionário específico para a sociedade civil organizada, a qual já era participante ativa da comissão, mas que passa então a ser contemplada com um instrumento específico, assim como os demais atores já usam.

Finalmente, o indicador 1.4 reforça a necessidade de divulgar os resultados por polo, prática já adotada para CPA da IES, mas que requer a busca por novas formas de comunicação, a fim de garantir o conhecimento da comunidade acadêmica acerca das fragilidades e potencialidades tanto da sede, quanto dos polos. Para este indicador, as ações já previstas no indicador 1.2 mostram-se como possibilidades a testar.

Em relação ao indicador 1.5 , sobre o relatório de autoavaliação, acredita-se que a avaliação deste documento com maior atenção, seja positivo para IES, a fim de promover melhorias no processo de registro e de acompanhamento das ações projetadas/concluídas, a fim de contemplar fluxos de análise, determinação e acompanhamento de providências pelas instâncias superiores. Contudo, neste indicador, a alusão "mudanças inovadoras" gera insegurança, a qual pode ser compreendida de forma subjetiva pelos avaliadores.

\section{CONSIDERAÇÕES FINAIS}

A cultura de Autovaliação Institucional, como ferramenta de diagnóstico e controle, está integrada à missão da Instituição, para que esta seja sempre a melhor solução de educação para a construção da sua própria história.

Por meio da Avaliação, são auferidos aspectos relativos à instituição e ao seu funcionamento, que também fazem parte das atividades de manutenção da excelência institucional e, por isso, constituem o procedimento geral de avaliação da Instituição. Tudo isso se faz necessário para que se atenda às necessidades institucionais, tornando-se um instrumento de gestão e ação acadêmico-administrativa de melhoria institucional conhecido pela comunidade acadêmica, uma comunidade sensibilizada por essas ações e que se beneficia e apropria dos resultados.

Neste movimento, cada setor considera suas políticas, seus fluxos e precisa organizar 
seu plano de ação, a fim de conquistar melhores resultados em uma próxima edição. É o momento também de se resgatar todas as melhorias realizadas no ano anterior, a fim de evidenciar a efetividade do trabalho da CPA na IES como órgão fomentador de melhorias.

Em relação aos polos, também é realizado um intenso trabalho de sensibilização, pois com a expansão da IES, muitos polos são novos e precisam de acompanhamento, a fim de que compreendam a cultura da avaliação institucional.

Assim, a divulgação da portaria 11 de junho de 2017 e do novo Instrumento de Avaliação Institucional Externa - Presencial e a Distância, em consonância com as estratégias do PNE para a elevação da qualidade do Ensino Superior no Brasil, devem ampliar a capacidade da CPA da IES na orientação e fomento de ações preventivas e corretivas, para nortear sua expansão, a melhoria da qualidade de oferta dos cursos e processos.

Neste cenário, as exigências de caráter regulatório, certamente trazem impacto não só à gestão da Instituição, mas para outras várias que também estão em processo de expansão, nas quais a atuação da CPA deve ser cada mais relevante, gerando a colaboração de vários setores, que juntos cooperam para que a Al realmente seja um instrumento de gestão imprescindível.

\section{REFERÊNCIAS}

ASSOCIAÇÃO Brasileira de Ensino a Distância. Censo EAD BR 2016. Disponível em: . Acesso em: 1 abr. 2017.

BRASIL. Instituto Nacional de Estudos e Pesquisas Educacionais Anísio Teixeira. Instrumento de Avaliação Institucional Externa. Brasília, DF, set. 2010. Disponível em: . Acesso em: 2 abr. 2017.

- Instituto Nacional de Estudos e Pesquisas Educacionais Anísio Teixeira. Nota Técnica INEP/DAES/CONAES n. 62. Brasília, 9 out. 2014. Disponível em: < http://www2.ifsp.edu.br/cpa/RelatolnstitucionalNotaTecnica62.pdf>. Acesso em: 2 maio 2017.

Lei ำ 13.005, de 25 de junho de 2014. Aprova o Plano Nacional de Educação (PNE) e dá outras providências. 2. ed. Brasília: Câmara dos Deputados, Edição Câmara, 2015. Disponível em: . Acesso em: 29 abr. 2017. 
Ministério da Educação. Secretaria de Educação a Distância. Referenciais de Qualidade para Educação Superior a Distância. Brasília, 2007. Disponível em:< http://portal.mec.gov.br/seed/arquivos/pdf/legislacao/refead1.pdf>. Acesso em: $1 \mathrm{abr}$. 2017.

Portaria Normativa n.11, de 20 de junho de 2017. Estabelece normas para o credenciamento de instituições e a oferta de cursos superiores a distância, em conformidade com o Decreto no 9.057, de 25 de maio de 2017. Diário Oficial da União, Brasília, DF, no 117, 21 jun. 2017. Disponível em: . Acesso em: 12 abr. 2017a.

- Instituto Nacional de Estudos e Pesquisas Educacionais Anísio Teixeira. Instrumento de Avaliação Institucional Externa - Presencial e a Distância. Recredenciamento. Transformação de Organização Acadêmica. Brasília, DF, out. 2017. Disponível em: . Acesso em: 12 abr. 2017b.

Decreto n. 9.057, de 25 de maio de 2017. Regulamenta o art. 80 da Lei. 9.394, de 20 de dezembro de 1996, que estabelece as diretrizes e bases da educação nacional. Brasília, DF, 25 de maio de 2017. Disponível em: . Acesso em: 2 abr. 2017c. 